\title{
CRIMINALIDAD, AMPARO Y LICENCIAS DE ARMAS EN LA CASTILLA DE FINALES DEL MEDIEVO
}

\author{
Óscar López Gómez \\ Universidad de Castilla-La Mancha
}

\section{RESUMEN}

El presente trabajo analiza el fenómeno de la concesión de licencias de armas por parte de la monarquía castellana durante los últimos ańos del siglo $\mathrm{xv}$, atendiendo a las motivaciones esgrimidas por los solicitantes, a las condiciones que se consideraban para su obtención y a su vínculo con la conformación de grupos armados y con el papel del sistema judicial. En virtud de ello, las 345 licencias de armas concedidas por el Consejo Real de Castilla que son objeto de estudio permiten aproximarnos a problemáticas como la de la criminalidad y el uso de las armas, los mecanismos establecidos de regulación de los conflictos sociales y los límites de la justicia. Los salvoconductos para transitar con cascos, broqueles, puñales o espadas nos sitúan en un escenario social apasionante, en el que convivían las presiones vecinales -la necesidad de mantener la fama; la honra en el ejercicio del derecho a la venganza-, las ansias de riqueza y la desesperación por sobrevivir.

Palabras clave: licencias de armas, Castilla, siglo xv, violencia, criminalidad, Consejo Real.

\section{CRIMINALITY, PROTECTION AND GUN LICENSES \\ IN LATE MIDDLE AGES CASTILE}

\section{Abstract}

This paper analyses the granting of arms licenses by the Castilian monarchy in the last years of the fifteenth century. It refers to issues such as motivations given by the applicants, conditions considered for obtaining them, their relations with development of armed groups and the role of the judicial system. 345 weapons licenses granted by the Royal Council studied allow us to approach problem of violence and use of weapons, regulation mechanisms of social conflict and limits of the royal justice in the Castilian Middle Ages. Documents for walking with helmets, broaches, daggers or swords put us in an exciting social setting, where coexisted desperation to survive with neighbourhood pressures -honour in the exercise of revenge- and desire for wealth -that led to forgive a death in exchange for a good bag of money-.

Keywords: Gun licenses, Castile, xv century, violence, criminality, Royal Council. 
Resulta complicado toparse con una licencia de armas original del siglo xv. Se trataba de una autorización con una idiosincrasia específica ${ }^{1}$, cuyo consentimiento por lo común era producto de una serie de motivaciones excepcionales; a priori relacionadas con la seguridad de un individuo o un conjunto de individuos, aunque, con frecuencia, en virtud de fines disimulados, cuando no ominosos ${ }^{2}$. Asimismo, no era un documento que hubiese que guardar bajo llave, en el interior de la vivienda. Quienes conseguían una credencial para ir con armas la debían traer encima a todas horas si no querían verse enredados en disturbios con los alguaciles, los cuales, dada su labor como valedores del orden, sobre todo en épocas de escándalos perseguían con acritud a los que circulaban con puñales, espadas, ballestas o lanzas, produciendo un sinnúmero de alborotos ${ }^{3}$. Por último, se trataba de cédulas con una vida limitada, que casi nunca excedía de los doce meses. Se supone que transcurrido este plazo quedaban sin valor, y los privilegiados por ellas automáticamente volvían a la legalidad, en la que el tránsito con armamento no era factible, a no ser que se trabajase en beneficio de la justicia. Hasta entonces, por el período que estableciese el salvoconducto, quienes lo poseían quedaban al margen de toda ley y toda proscripción ${ }^{4}$, pudiendo ir con armas de día y de noche, por todos los territorios, e, incluso, haciéndose acompañar por una escolta 5 .

1 Siglas utilizadas: AGS: Archivo General de Simancas. CCA: Cámara de Castilla. CED: Cédulas. RGS: Registro General del Sello.

2 Córdoba de la Llave, Ricardo, «Violencia cotidiana en Castilla a fines de la Edad Media», en Iglesia Duarte, José Ignacio de la (coord.), Conflictos sociales, politicos e intelectuales en la España de los siglos XIV y XV. XIV Semana de estudios medievales, Nájera, del 4 al 8 de agosto de 2003, Logrońo, 2004, pp. 393-443, en concreto p. 385.

3 El caso de Toledo es paradigmático. Por ejemplo, la noche del 31 de enero al 1 de febrero de 1507, con la ciudad escandalizada, en la plaza situada delante de la casa del conde de Fuensalida, que aún existe, un alcalde de la ciudad, Diego de Pedrosa, iba a buscar al escribano Antonio de Madrid, y entre la casa del dicho señor conde de Fuentsalida e la casa de don Juan de Ayala, que es más abaxo del antepecho de la casa del dicho conde, junto con el horno, falló juntos a Pedro Tornero, e a Gugillo, e a Pedro Presbitero, e a su hermano de Juan Jurado que se dize Sant Pedro, e [a] Alfonso de Carpio. E que quando este testigo llegó çerca d'ellos, yendo por su calle adelante seguramente con su vara de justiçia en la mano, que los susodichos se repararon e pusyeron las manos en las espadas y en los broqueles. E que este que depone les dixo: "¿Qué es eso? ¿Entabláys os?». Y que el dicho Pedro Platero e (blanco) de Sant Pedro respondieron, e dixeron: "Asý pensamos que herades alguazil, y por eso echamos mano a estas cartas de corona...». El tono burlesco de la provocación es evidente. AGS, CC, Pueblos, leg. 20, fol. 220. Sobre los contextos de alteración social en la Toledo del siglo xv véase López Gómez, Óscar. «La çibdad está escandalizada. Protestas sociales y lucha de facciones en la Toledo bajomedieval». Studia historica. Historia medieval, 2016, vol. 34, p. 243-269.

${ }^{4}$ Con fórmulas como ca nos por la presente alçamos el dicho vedamiento en quanto a esto atañe. AGS, RGS, leg. 147801, exp. 114. O, por ejemplo: ca nos las revocamos e damos por libres e quitos dellas a ellos e a sus bienes: AGS, RGS leg. 147809, exp. 151.

5 ... libremente, de dia e de noche, por esas dichas çibdades e villas e logares, e por cada una dellas, asý ofensyvas como defensyvas. E se las non tomedes ni mandedes tomar nin les prendades los cuerpos por traher las dichas armas, nin fagades nin mandedes faser otro dapno alguno en sus personas nin en los dichos sus bienes, ca yo [la autoridad correspondiente] les doy liçençia para que puedan traher las dichas armas syn pena alguna, non enbargante qualesquier ordenanças e mandamientos e defendimien- 
La concesión de este tipo de autorizaciones solo de forma excepcional, su tenencia en manos privadas y su carácter efímero son los elementos que hacen que no sea fácil encontrárselas en un archivo histórico. Ni tan siquiera está claro para qué servían. En el Medievo los vecinos de todas las poblaciones estaban en la obligación de tener armas en sus hogares, pero únicamente habían de acudir a ellas de ser convocados por la justicia: en contra del crimen, o en amparo de la paz. Los integrantes del común, de la mayoría social, ostentaban la doble condición de pecheros y peones de guerra, lo que suponía un peligro constante, puesto que, si de por sí resultaba complicado vedar la circulación de armas por las calles cuando, merced a sus virtudes, el gobierno exigía a la población que las poseyese, más difícil aún era soslayar el hecho de que ir armado en aquellos siglos, como hoy, confería a la persona un incuestionable grado de seguridad, por mucho que la convirtiese en un potencial malhechor.

Según ha venido remarcando la historiografía sobre la materia ${ }^{6}$, buena parte de los hombres circulaban con armamento: oculto, por una pulsión defensiva, disi-

tos et estatutos que ayades fecho o fisyeredes sobre rasón del traher de las dichas armas...: AGS, RGS, leg. 147708, exp. 420.

${ }^{6}$ La bibliografía en torno al crimen, la violencia y la justicia para la Baja Edad Media es ingente. Solo en los últimos años podrían traerse a colación aportaciones de relevancia como CARLSMiтh, Christopher, «Student Violence in Late Medieval and Early Modern Bologna», en Rubin Blanshei, Sarah (edit.), Violence and justice in Bologna. 1250-1700, Lanham, 2018, pp. 207-225; Solórzano Telechea, Jesús Ángel, Haemers, Jelle y Czaja, Roman (eds.), Exclusión y disciplina social en la ciudad medieval europea. Logroño, 2018; CHALlET, Vincent, «Violence as a political language: the uses and misuses of violence in late medieval French and English popular rebellions», en Firnhaber-Baker, Justine y Schoenaers, Dirk (eds.), The Routledge history handbook of medieval revolt, Londres, 2017, pp. 279-291; Sposato, Peter W., "Chivalry and Honor-Violence in Late Medieval Florence», en Nakashian, Craig M. y Franke, Daniel P. (publ.), Prowess, piety, and public order in medieval society: studies in honor of Richard W. Kaeuper, Leiden, 2017, pp. 102-119; BeLlo León, Juan Manuel, «La violencia contra el mercader y los medios para protegerse en la Andalucía Atlántica de finales de la Edad Media». Clio \& Crimen, 2017, vol. 14, pp. 229-262; ŽIvkovic, Valentina, "Criminal offenses and violence in medieval Kotor (1326-1337)», en Ravancic, Gordan (publ.), Our daily crime. Collection of studies, Zagreb, 2014, pp. 103-118; CóRdoba de LA Llave, Ricardo, "Conflictividad social en los reinos hispánicos durante la Baja Edad Media: aproximación historiográfica». Vinculos de Historia, 2014, vol. 3, pp. 34-53; Magina, Adrian, "Cum manibus armatis. Facets of violence in the medieval Banat». Banatica, 2014, vol. 24/2, pp. 47-64; ZorZI, Andrea, «Rituals of Youthful Violence in Late Medieval Italian Urban Societies», en Cohn, Samuel K., Fantoni, Marcello y Franceschi, Franco (publ.), Late Medieval and Early Modern Ritual. Studies in Italian Urban Culture, Turnhout, 2013, pp. 235-266; Jansen, Katherine Ludwig, “Pro bono pacis”: Crime, Conflict, and Dispute Resolution. The Evidence of Notarial Peace Contracts in Late Medieval Florence», Speculum, 2013, vol. 88, pp. 427-456; González Zalacaín, Roberto, La familia en Castilla en la Baja Edad Media: violencia y conflicto. Madrid, 2013; CóRdoba de LA Llave, Ricardo, «El combate contra el delito: la justicia criminal en el siglo XV». Andalucia en la historia, 2013, vol. 41, pp. 8-13; Terry-Fritsch, Allie y Mitchell, W.J. Thomas (publ.), Beholding violence in medieval and early modern Europe. Burlington, 2012; Ricciardelli, Fabrizio, «Violence and Repression in Late Medieval Italy», en Samuel K. Cohn Jr y Ricciardelli, Fabrizio (eds.), The Culture of Violence in Renaissance Italy, Florencia, 2012, pp. 55-80; BAzÁn DíEz, Iñaki, «La utilidad social del castigo del delito en la sociedad medieval: "para en exemplo, terror e castygo de los que lo ovyesen"», 
mulado entre las ropas ${ }^{7}$; o a la vista, dada la justificación que concedía su uso práctico -para comer o cortar, o por dedicarse a oficios que lo demandaban, como el de carnicero o pescadero-, o meramente como una muestra de poderío, en el caso de la caballería ${ }^{8}$. La cultura de la violencia iba, y va aún hoy, en contra de toda restricción al empleo de las armas, y haría que, a pesar de las contravenciones, no se consiguiera confinar su circulación en Europa hasta bien entrado el siglo xIX. El anhelo de una protección real e inmediata movía a su uso, generándose un «efecto dominó" por contagio psicológico, ya que en toda sociedad armada hay una presión que condiciona al sujeto; que lo empuja a convertirse en uno más ${ }^{9}$, y a adquirir no solo protección, sino un estatus de equivalencia y consonancia. Por estos motivos, no son fáciles de comprender las razones por las cuales algunas personas rogaron a los reyes su venia para circular con armamento. Si todo el mundo lo llevaba, ¿para qué servía? ¿'Tales individuos no eran capaces de garantizar su propia protección sin la pérdida de tiempo y maravedíes que conllevaba toda solicitud en la corte?

Desde nuestro punto de vista, no resulta apropiado hablar de un único fin a la hora de referirnos a las licencias de armas. Según Ricardo Córdoba de la Llave, en tanto que autorización "para utilizarlas en defensa propia en el momento en que fuera necesario", tenían un sentido finalista -no puramente disuasorio ${ }^{10}$, , que nos descubre la realidad del crimen y del delito en aquella época del pasado. Empero, las licencias de armas eran, además, herramientas al servicio de personas que vivían disputas de todo tipo, origen de presiones y encontronazos. De conseguir una merced de esa naturaleza, para andar con armamento, quien lo lograba podía situarse en una posición de fuerza: al margen de la ley, y con las intimidaciones de que hiciera uso de alguna forma refrendadas. Por tanto, eran instrumentos con cierta repercusión en los conflictos, que, al conferir legitimidad a la salvaguarda de quienes las conseguían, desacreditaban a los rivales, poniéndolos en una embarazosa situación de inferioridad. Los peticionarios de los permisos para traer armamento siempre se presentaban como víctimas, como la parte débil en una querella, justificándose en

en López OJEDA, Esther (coord.), Los caminos de la exclusión en la sociedad medieval. Pecado, delito y represión: XXII Semana de Estudios Medievales, Nájera, del 1 al 5 de agosto de 2011, Logrońo, 2012, pp. 447-475; Titone, Fabrizio, «Presentation and Practice of Violence in Late Medieval Sicily in Piazza, Polizzi and Randazzo», en ibidem, pp. 145-166; Karbic, Damir, «The Thin Border Between Justice and Revenge. Order and Disorder: Vrazda (Enmity) and Institutional Violence in Medieval Croatia», en Miljan, Suzana y Jaritz, Gerhard (eds.), At the Edge of the Law: Socially Unacceptable and Illegal Behaviour in the Middle Ages and the Early Modern Period, Krems, 2012, pp. 9-20.

7 Córdoba de la Llave, Ricardo, «Violencia cotidiana en Castilla...», pp. 442-443.

8 Asenjo González, María, "Preparar la paz y prevenir la guerra en las ciudades bajomedievales», en Arranz Guzmán, Ana, Rábade Obradó, María del Pilar y Villarroel GonzáLez, Óscar (publ.), Guerra y paz en la Edad Media, Madrid, 2013, pp. 109-140, en concreto p. 123.

9 Sobre todas estas cuestiones véase López Gómez, Óscar, «Licencias de armas y conflictividad social en la Castilla de finales del siglo xv», en Ruiz Gómez, Francisco (dir.), La ciudad medieval. Nuevas aproximaciones. Homenaje al profesor Ricardo Izquierdo Benito, Cuenca, UCLM, 2019 [en prensa].

10 Córdoba de la Llave, Ricardo, «El homicidio en Andalucía a fines de la Edad Media. Primera parte». Clio \& Crimen, 2005, vol. 1, pp. 278-504, en concreto p. 390. 
su derecho a la defensa. El objetivo era conseguir un espacio más allá de la ley, en el que no pudiesen resguardarse sus adversarios. Y, por si fuera poco, por último, también era significativa la consideración simbólica, dadas las ausencias en las restricciones que definían a este tipo de merced, según las cuales, frente a los demás individuos, los poseedores de un visado para ir con armamento lo podían traer a la vista, sin obstáculos, lo que únicamente les estaba permitido a las autoridades y, a pesar de los impedimentos, a la caballería.

A tenor de estas circunstancias, los salvoconductos para andar con lanzas, cascos, broqueles, puñales, espadas y demás artefactos ofensivos e defensivos nos trasladan a un escenario social apasionante, lleno de matices, donde convivían las presiones vecinales -la necesidad de mantener la fama; la honra en el ejercicio del derecho a la venganza ${ }^{11}$ - y las ansias de riqueza -que llevaban a indultar una muerte a cambio de una buena bolsa de maravedíes- con la desesperación por sobrevivir. Por fortuna, aunque tropezarse con una licencia original del siglo XV sea difícil, sí se conservan cientos de duplicados de la época en los archivos de las instituciones con potestad para otorgarlas. Instituciones que se podrían dividir en dos grandes ámbitos, según parece. Por un lado, el ámbito central, de la corte, y, por otro, el local, donde todo indica que corregidores, asistentes, alcaldes y demás sujetos con oficios de alto nivel -inquisidores, alcaides, monederos, capitanes de la hermandad-gozaban de la prerrogativa de otorgar esta autorización ${ }^{12}$. En el día a día de la gestión del gobierno municipal, sin embargo, era un tipo de merced extraño, a no ser que previamente hubieran intervenido los consejeros reales. Las disposiciones en pro del orden público consistían en lo opuesto: en impedir el tránsito con armas, a la par que se establecían toques de queda al anochecer, se organizaban rondas de vigilancia, se proscribía el juego y se ordenaba desterrar a vagamundos e rufianes e omes sin dueño nin señor conosçido ${ }^{13}$. En consecuencia, la institución de gobierno que más se preocupó por las implicaciones del asunto de las armas fue el Consejo Real: el órgano que dirigía la política de la corona, para el que la cuestión siempre fue peliaguda y de encaramiento difícil, en la medida en que en ella confrontaban tres realidades: las circunstancias del momento, frente a las que la capacidad de acción de la justicia era reducida; lo necesario de ofrecer amparo a quienes así lo solicitaban; y

11 Guerrero Navarrete, Yolanda, «Orden público y corregidor en Burgos (siglo xv)». Anales de la Universidad de Alicante. Historia medieval, 2000-2002, vol. 13, pp. 59-102.

12 En una carta del Consejo Real que se dirigió a las autoridades de Medina del Campo, en 1499, se decía que Sancho de Ortega, vecino de la localidad, se había quejado, diciendo que hacía un año, más o menos, Fernando Escuriano, vecino de la villa, había tenido con él ciertas cuestiones, y que Pedro Maldonado, un alcalde, viendo su ynoçençia, e no aver sydo a su cargo e culpa de las dichas questyones, le dio liçençia para defensyón de su persona, segúnd dis que paresçe por un testimonio de que ante nos fasýa presentaçión, e que, non embargante que vos fa mostrado la ynformaçión e liçençia que tyene para trafer las dichas farmas del dicho alcalde dicho, que no lo avéys querido ni queréys dar la dicha liçençia para que las pueda trafer, aunque fos da nueva ynformaçión de cómo el dicho Fernando Escuriano a venido secretamente a esa dicha villa por le matar: AGS, RGS, leg.149910, exp. 131.

13 Gonthier, Nicole, Le châtiment du crime au Moyen Âge. Leroy, 1998, p. 39 y ss. 
lo obligatorio de mantener el orden ${ }^{14}$, si es que se pretendía que imperase un cierto ambiente de paz.

\section{LA CIRCULACIÓN DE LAS ARMAS Y LOS PELIGROS PARA LA PAZ}

Los consejeros reales pretendían imponer una pas e sosyego que se adecuara a los intereses de la corona ${ }^{15} \mathrm{y}$, con tal objetivo, si bien de forma primordial se ocupaban de las causas más complejas, como los alborotos, realmente intermediarían en todo lo que estimaron oportuno ${ }^{16}$, imponiendo como propias de su labor cuestiones esenciales para sus fines como el nombramiento de cargos públicos, la tutela de sus delegados en cada una de las villas y ciudades - con el envío de jueces pesquisidores-, la regulación de los tributos y, especialmente, la concesión de licencias de $\operatorname{armas}^{17}$. El Consejo no dudó a la hora de sancionar los estatutos que prohibían la circulación con artefactos peligrosos en la mayor parte de las regiones, aunque era muy consciente de las dificultades para que los vetos se cumplieran a rajatabla, y nunca descartó la posibilidad de intervenir el tránsito con armas y disciplinarlo, para establecer un régimen de seguridad en el que no hubiera dudas sobre quiénes podían traerlas - más allá de los caballeros, cuya actitud era desafiadora-: los servidores en los oficios de gobierno o justicia, los que trabajasen para ellos mientras estuvieran en su compañía, e, igualmente, las personas que se encontraran en una situación de peligro.

A finales del siglo xv la prohibición de llevar armas estaba instituida en todos los territorios de Castilla, regulada en los estatutos y ordenamientos locales. En el derecho municipal solían existir una o varias leyes en las que se reglamentaba la prohibición de transitar por las calles con pertrechos ofensivos e defensivos, así como sus límites y sus excepcionalidades. En unos casos la legislación era muy laxa ${ }^{18}$; y en otros minuciosa ${ }^{19}$. A veces las medidas a tomar frente a aquellos que iban en con-

14 Dios, Salustiano de, El Consejo Real de Castilla (1385-1522). Madrid, 1982, p. 243.

15 López Gómez, Óscar, "Pas e sosyego. Un argumento de acción política en la Castilla bajomedieval». Medievalismo: Boletin de la Sociedad Española de Estudios Medievales, 2006, vol. 16, pp. $41-72$.

16 Kagan, Henry, Pleitos y pleiteantes en Castilla, 1500-1700. Salamanca, 1991, p. 129.

17 Dios, Salustiano de, El Consejo Real de Castilla (1385-1522), p. 243.

18 Longas Bartibas, Pedro, "Ordenanzas municipales de Ezcaray». Anuario de historia del derecho español, 1961, vol. 31, pp. 465-472, cap. 3, p. 466; Enjo Babío, Ascensión y Antonio Rubio, María Antonia de, «Ordenanzas municipales de Ourense en el siglo xv. Estudio introductorio». Cuadernos de estudios gallegos, enero-diciembre 2006, vol. LIII/119, pp. 211-230; Porras ArboLEDAs, Pedro Andrés, «El procedimiento gubernativo del concejo de Toledo a fines del siglo xv: la fijación de las pechas de las aldeas». En la España medieval, 2005, vol. 28, pp. 125-153, capítulo 18, en concreto pp. 151-153.

19 Arízaga Bolumburu, Beatriz y Val Valdivieso, María Isabel del, «La villa de Guernica en la Baja Edad Media a través de sus ordenanzas», La villa de Guernica a través de sus ordenan- 
tra de la prohibición solo implicaban la pérdida de los adminículos y una multa; y a veces se establecían condenas de azotes y de cárcel $^{20}$. En lo que sí se coincidía era en la importancia de la paz social y, por ello, en el rol de los alguaciles encargados de hacer que se cumplieran las leyes. Unos alguaciles que no debían permitir extorsiones ni chantajes, y que habían de tener en cuenta los límites existentes a la hora de cumplir con su labor. El primero, en cuanto al papel de cada persona, ya que ciertas restricciones solo repercutían en los ciudadanos sin oficios de gobierno, no en corregidores, jueces de residencia, pesquisidores, alcaldes o los referidos alguaciles, que podían ir con armas e, incluso, con hombres armados. En segundo lugar, los vetos tenían una existencia muy condicionada, quedando sin valor de producirse una solicitud de auxilio por parte de las autoridades. Una de las obligaciones inherentes a la condición de vecino consistía en la exigencia de que, tras escuchar un toque de campanas o gritos de socorro, había que salir a las calles con armamento, en favor de la justicia y de las vidas y los bienes de los conciudadanos. A lo que habría que sumar un tercer límite, en este caso doble: la problemática con la caballería, que por su antigua raigambre guerrera se consideraba con el derecho a traer armas; y las tensiones fruto de que el Consejo Real -por los motivos que fuera- hubiera tolerado ir con espadas, broqueles o paveses a algunos hombres del común, en contra de la ley.

Independientemente de la actitud abusiva de algunos alguaciles, es lógico que se produjeran trifulcas a causa de las limitaciones de las ordenanzas y que, por sus abusos o por sus cometidos, soliesen ser protagonistas en la violencia que se producía a diario. Su tarea los ponía en una situación dificultosa ${ }^{21}$, que hizo que a algunos no les quedase más remedio que solicitar ayuda, una vez que dejaron sus oficios ${ }^{22}$. Por ejemplo, en 1493 presentó una demanda ante el Consejo Real un alguacil de la villa de Olmedo, que había trabajado con el alguaçil de la corte Antón de Morales y con el juez pesquisidor Juan de Ayala. Dados sus cometidos -derribar edificios ilegales, prender a facinerosos, ejecutar condenas físicas y sentencias a muerte- ${ }^{23}$, muchos le tenían gran odio e enemistad. El alguaçil de la corte Francisco de Riańo, por su parte, un vecino de Burgos, denunció ser víctima de un notorio número de

zas, San Sebastián, 1986, pp. 169-233; Morollón Hernández, Pilar, «Las ordenanzas municipales antiguas de 1400 de la ciudad de Toledo". Espacio, tiempo y forma. Serie III. Historia medieval, 2005, vol. 18, pp. 265-439; González Jiménez, Manuel, «Ordenanzas del concejo de Córdoba (1435)». Historia. Instituciones. Documentos, 1975, vol. 2, pp. 189-316, capítulo 340, p. 281.

20 Galán Parra, Isabel, «Las ordenanzas de 1504 para Huelva y el Condado de Niebla». Huelva en su Historia 3 (2011): 107-174. Ordenanza 94, p. 127.

21 Por ejemplo, en Cuenca, en 1411, se denunció a un alguacil que traía consigo a las tales vezes en su compañia rufianes e onbres malos que tienen e tenian mançebas públicas en las mancebias, de lo que se sigue mucho danno a la çibdad de muchos cohechos, de furtos e malefçios que fasian... Citado en Córdoba de la Llave, Ricardo, «El homicidio en Andalucía...», p. 390.

22 AGS, RGS, leg. 148606, exp. 91.

$23 \mathrm{Su}$ demanda de ayuda se tomó en serio, otorgándosele permiso para ir armado durante dos años, de día y de noche, hasta comienzos de 1495: AGS, RGS, leg. 149302, exp. 238. No obstante, el enfrentamiento con sus enemigos siguió, y hubo de solicitar otra licencia en 1499: AGS, RGS, leg. 149910, exp. 17. 
amenazas, merced a lo cual se le autorizó para que lo escoltasen cuatro hombres durante doce meses ${ }^{24}$. También requirieron asistencia Alonso Bocalán, alguacil salmantino ${ }^{25}$; el alguacil de la hermandad en Sevilla Alfonso de la Cueva ${ }^{26}$; el alguacil toledano Juan de Porres ${ }^{27}$; Diego de Illescas, alguacil de las villas del maestrazgo de Santiago ${ }^{28}$; o el conquense Álvaro de Molina ${ }^{29}$, a quien amenazaban con que habían de matarlo en qualquier manera que le pudieren tomar, a cabsa qu'él seyendo nuestro alguasyl en la çibdad de Trugillo e villa de Medina del Campo prendió e tomó armas a muchas personas, e fiso otras cosas en presençia de la nuestra justicia.

\subsection{Los cambios de postura del Consejo Real}

Se desconoce el número de solicitudes presentadas ante los consejeros reales que nunca fructificaron. Los individuos en busca de su socorro tenían que perseguirlos en su continuo deambular de una comarca a otra, financiándose de su bolsillo su permanencia en cada una de las localidades, su manutención y las gestiones que había que concretar para ser atendidos; algo que, además de oneroso, podía alargarse durante meses ${ }^{30}$. Por esta razón, es lógico que en ocasiones la empresa no llegara a buen puerto, aunque, en otras, al contrario, los beneficios fueran notables; hasta el punto de conseguirse no una, sino dos mercedes. El bachiller Diego Gómez de Baeza, por ejemplo, un procurador de Chinchilla partidario del bando isabelino en la guerra frente a la princesa Juana, llegó a la corte a inicios del otoño de 1477 diciendo que, dada su posición política, le querían mover litigios y acusaciones; gracias a ello obtuvo una primera merced, en la que el Consejo le ponía, a él y a los suyos, e sus bienes, en nuestra guarda, seguro e amparo e defendimiento real ${ }^{31}$. Unos meses más tarde, en enero de 1478, bajo la alegación de que habían matado a uno de sus hermanos y perseguían a sus parientes, Gómez de Baeza logró otro permiso para que, con algunos de los que con'él andoviesen, podiesen traer armas, aunque las armas fuesen vedadas ${ }^{32}$.

De cara a la realización de este estudio, partiendo de las posibilidades que permite el Portal de Archivos Españoles (PARES), se ha configurado una base de

${ }^{24}$ AGS, RGS, leg. 149402, exp. 128.

25 AGS, RGS, leg. 149302, exp. 233.

26 AGS, RGS, leg. 150101, exp. 12.

27 AGS, RGS, leg. 150106, exp. 24

28 AGS, RGS, leg. 150003, exp. 24; AGS, RGS, leg. 150106, exp. 27.

29 AGS, RGS, leg. 149504, exp. 10.

30 Aún no se han hallado las cuentas que registraban los pagos por la gestión de este tipo de documentos. Lo mismo ocurría con los perdones. Véase González Zalacaín, Roberto, «El perdón real en Castilla: una fuente privilegiada para el estudio de la criminalidad y la conflictividad social a fines de la Edad Media. Primera parte. Estudio», Clio \& Crimen. Revista del Centro de Historia del Crimen de Durango, 2011, vol. 8, pp. 290-352, en concreto pp. 339-340.

31 AGS, RGS, leg. 147710, exp. 81.

32 AGS, RGS, leg. 147801, exp. 114. 


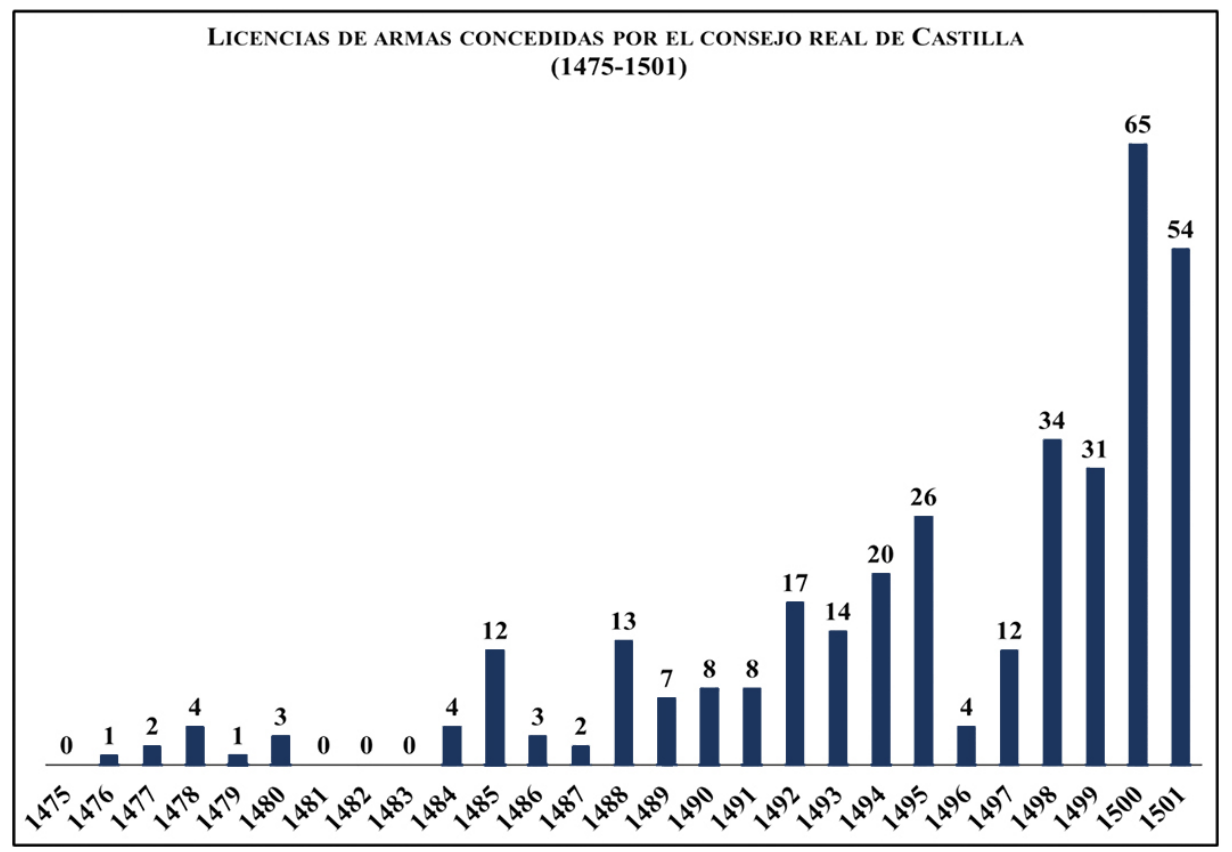

datos con 345 copias de licencias para ir con armamento concedidas en nombre de los reyes durante un período de veintiséis años: de 1475 a 1501. Puesto que se trata de la práctica totalidad de las autorizaciones otorgadas por el Consejo Real en dichas fechas, o al menos de todas las que han dejado un vestigio, de su simple análisis numérico se pueden extraer varias conclusiones. En primer lugar, en torno a la soberanía regia, ya que 345 credenciales no son muchas, teniendo en cuenta que se está estimando a toda la población de Castilla, a más de cuatro millones de personas, para un período de tiempo de más de dos décadas y media. Podría pensarse que el dato denota un raquitismo demoledor en la capacidad de influencia del poder monárquico en la vida de sus súbditos. No obstante, el número no tiene tanto que ver con dicha capacidad, que evidentemente era exigua, sino con un deseo de no concederlas.

Las causas por las cuales a partir de la década de 1490 se incrementó el número de permisos de armas nos son desconocidas. A priori, tendría que ver con motivaciones de carácter múltiple, relacionadas con un deterioro de la paz social, con elucubraciones de los propios consejeros acerca de lo perentorio de amoldarse a unos tiempos en los que, como toda la comunidad llevaba armas, podía ser más efectiva una regularización de su tránsito que un veto absoluto, e, inclusive, con razones de naturaleza económica, por la necesidad de la monarquía de conseguir dinero a cambio de mercedes. Con todo, existe otra razón indiscutible. Con los años el Consejo dejaría de viajar con la corte, y, dividido en dos sedes, se asentaría casi permanen- 


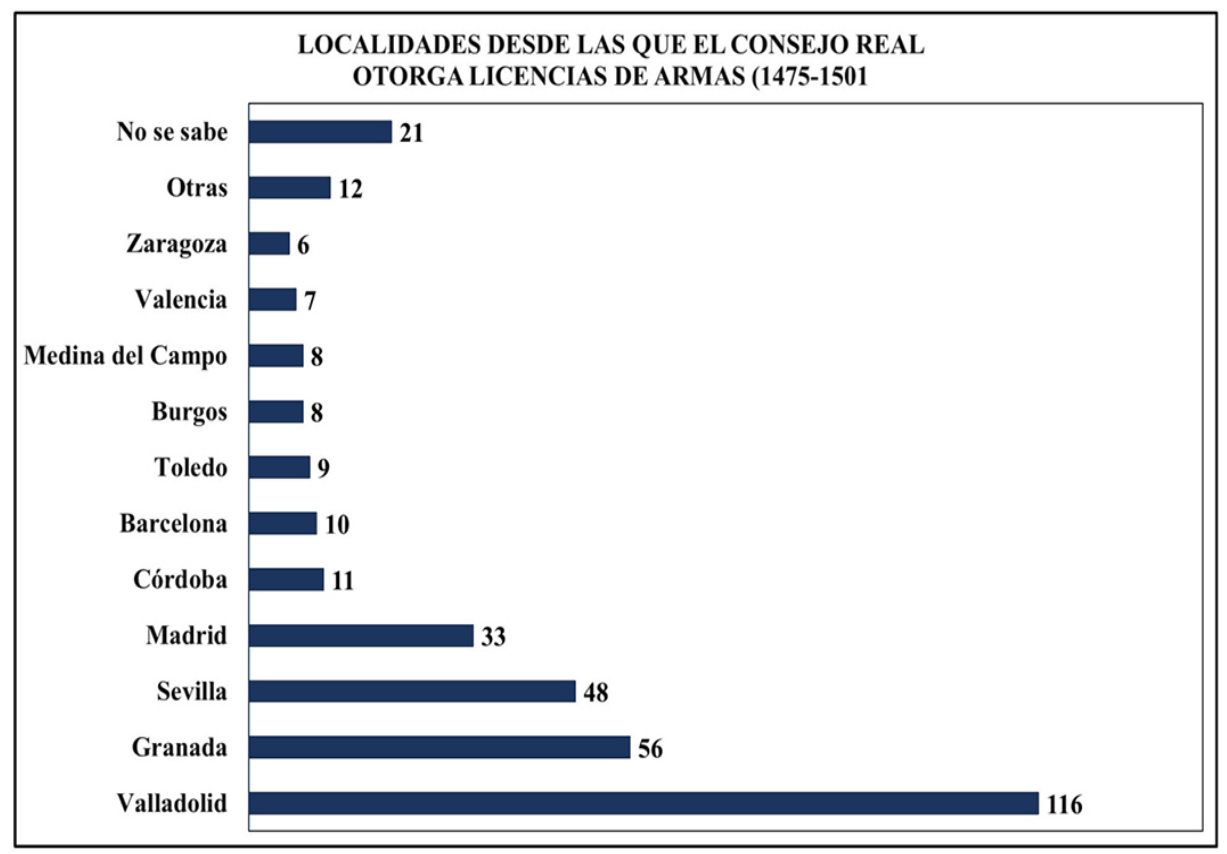

temente en dos localidades: Valladolid, al norte, y Granada, al sur. Esto permitió a los peticionarios de auxilio no tener que indagar sobre el sitio en que se hallaban los consejeros, no tener que ir en su búsqueda durante días y, por ende, ahorrar gastos, lo que hizo que aumentaran las solicitudes.

Sería interesante evaluar este devenir hasta épocas más avanzadas, próximas a la rebelión de las comunidades. En algunas de las urbes más turbulentas, como en el caso de Toledo, el número de licencias concedidas a la postre sería pernicioso, erigiéndose en una de las causas de la rebelión de $1520^{33}$. En Salamanca, por su parte, tras la muerte de Pedro de Miranda a manos de dos hombres, Suero de Corbella y Diego de Villafuerte, la familia del fallecido requirió el socorro de la corona, consiguiendo en octubre de 1484 una licencia para que transitasen armados Alfonso Flores y Gómez de Miranda, hijos de Catalina, una hermana del difunto, así como el resto de sus sobrinos, sus familiares y los continuos comensales que con ellos convivían $^{34}$. Lejos de resolverse la disputa, el hecho de conceder una licencia de armas

33 López Gómez, Óscar, Violencia urbana y paz regia: el fin de la época medieval en Toledo (1465-1522), tesis doctoral defendida en noviembre del año 2006, http://hdl.handle.net/10578/2771 [RUIdeRA: Repositorio Universitario Institucional de Recursos Abiertos. Universidad de Castilla La Mancha], capítulo 7.2.3.1. Amparar a la población armándola, p. 1522 y ss.

${ }^{34}$ AGS RGS, leg. 148410, exp. 1 y exp. 2. 
colectiva creó un problema de orden público, al que inmediatamente darían respuesta los consejeros, en una carta al corregidor de la urbe ${ }^{35}$ :

... agora a nos es fecha relaçion que sy todas las personas quien nos asý dimos la dicha liçençia para traer las dichas armas las oviesen de traher en la dicha çibdad se podrían recresçer ruydos e muertes de omes, e otros inconvenientes, de que a nos se recresçería deservicio, lo qual, por los el nuestro Consejo visto, fue acordado que nos deviamos mandar dar esta carta para vos, en la dicha rasón, por la que vos mandamos que a dos fijos de la dicha dońa Catalina e a Juan de Villafuerte, vesinos de la dicha çibdad, dedes e consyntades traher las dichas armas por el tiempo e segúnd que en la dicha nuestra carta se contiene, con tanto que sus omes nin criados dellos nin de alguno dellos nin de Juan de Villafuerte non trayan las dichas armas [...] e sy algunas personas de más de los susodichos troxieren las dichas armas por virtud de la dicha nuestra primera carta se las tomedes e fagades tomar, e non consintades ni dedes lugar que ellos ni algunos dellos las trayan con el thenor e forma desta dicha nuestra carta ${ }^{36}$.

Estos cambios de postura del Consejo Real respecto al asunto de las armas no eran excepcionales, si bien para entenderlos habría que partir de una triple consideración. En primer lugar, y como ya se ha indicado, el mantenimiento de la paz regia - de la paz que los reyes deseaban que reinase ${ }^{37}$ - era un fin concluyente, que no entendía de cambios de proceder, de formas de actuar ni de subterfugios, y que lo condicionaba todo. La idea de que lo determinante eran los fines, y no los medios, era axiomática y gozaba de absoluta prevalencia. Aun así, en segundo lugar, el reinado de Isabel se inició con una pugna por el trono con la princesa Juana, en medio de un conflicto bélico extraordinario, en el que, dado el peligro de la situación, el armamento se movía sin obstáculos, con riesgo para el orden público. Habría que esperar a que la guerra pasase para que los procedimientos se empezaran a pulir, en aras de ejercer una mayor efectividad gubernativa. Si antes de los Reyes Católicos se habían autorizado licencias de armas, lo cierto es que no existía una formulación burocrática inamovible. El salvoconducto poseía cláusulas definitorias que no se concretaron con rigor hasta la década de $1490^{38}$, por lo que la omisión de algunas de ellas se supone que se debería suplir de acuerdo a lo tradicionalmente establecido.

En general eran cuatro las cláusulas a tener en cuenta en toda autorización para ir con armamento: el número de hombres a los que se ofrecía el salvoconducto, los meses durante los cuales estaría en vigor, y dos exigencias delimitadoras, cuya

35 AGS, RGS, leg. 148411, exp. 58

36 Unos meses después, en enero de 1485, Catalina de Miranda y los suyos lograrían una nueva licencia de armas, pero esta vez más específica, estableciéndose que solo pudieran traerlas seis personas: Diego de Ojeda, Juan de Ojeda, Antonio de Ojeda, Alonso Flores, Bernal de Mata y García de Padilla: AGS; RGS, leg. 148501, exp. 3.

37 Sobre este concepto véase López Gómez, Óscar, Violencia urbana y paz regia...

38 Sobre este protocolo para el caso de Portugal véase Duarte, Luis Miguel, Justiça e criminalidade no Portugal Medievo (1459-1481). Oporto, 1993, pp. 290-291. 
no observancia lo dejaría todo sin validez: la obligatoriedad de llevar a cabo una pesquisa, con el fin de asegurarse de que no era una ańagaza lo referido en el Consejo; y la entrega en depósito de unos bienes y un capital lo suficientemente gravosos como para impedir que el uso del armamento no fuera el demandado. Tales cláusulas comenzaron a introducirse sobre todo en la década de 1480, desde la cual el Consejo exigiría a otras autoridades que, por mucho que una averiguación lo justificara, no consintieran un permiso suyo si quienes iban a caminar armados no ofrecían fianças llanas e abonadas, en prueba de que con las dichas armas non ofenderian a persona alguna, e que solamente las trayrían para defensión de su person ${ }^{39}$. La directriz que se siguió, en la medida en que el visado de armas fue concretándose, consistiría en reclamar unas fianzas suficientes, en delimitar el período de validez de las autorizaciones -reduciéndolo a lo imprescindible: a un año ${ }^{40}$-, en permitir su uso en todo el territorio, excepto donde se hallaran la corte o el Consejo ${ }^{41}$, y, especialmente, en controlar el número de hombres autorizados, con el fin de evitar la creación de posibles bandas de malhechores.

\subsection{LA FORMACIÓN DE GRUPOS ARMADOS}

Aunque la concesión de una credencial a un individuo concreto para que él, y solo él, pudiera ir con armas, no siempre era garantía de protección -sus agresores podían ser numerosos-, los consejeros buscarían circunscribir sus mercedes lo máximo posible, de cara a evitar que se organizasen grupos armados. En las licencias analizadas se autorizó a circular con armamento de forma específica a 613 individuos, además de a 19 grupos - cuyo número de integrantes no se concretaba- y a una colectividad de vecinos: la tierra de Berástegui, en la divisoria entre Navarra y Castilla ${ }^{42}$. En el 60,86\% de los casos el salvoconducto era privativo, para una per-

39 AGS, RGS, leg. 148804, exp. 158.

40 De las 345 licencias, en 53 casos -el 15,36\% - no se establece una duración determinada. De forma excepcional, en cuatro licencias, hay lapsos de tiempo de cuatro meses, tres ańos, cinco ańos y durante un pleito. En siete casos se acuerda una validez de seis meses, de dos años en ocho, lo que determine la autoridad local en dos, y durante el desempeño de un oficio en cuatro. En la gran mayoría, en 267 licencias -77,39\%-, la duración establecida es de un año, a contar desde la fecha del documento.

$41 . .$. eçebto que las dichas armas non las pueda trafer en la nuestra corte, donde nos estovieremos, porque nos avemos mandado e defendido que en la dicha nuestra corte no se traygan las dichas armas...: AGS, RGS, leg. 149906, exp. 3. La fórmula de prohibir traer armas en la corte empezó a especificarse en el año 1499. En las licencias expedidas en Granada solo se decía que no se trajeran en la corte. En las que redactaban en Valladolid dicha prohibición sí se hacía extensiva a ese lugar.

42 Se alzó la prohibición de llevar armas porque, según algunas quejas, al estar la tierra de Berástegui en una zona fronteriza con Navarra, en época de guerras y conflictos había habido muertes y tomas, robos y diferencias y otras injurias, de la una parte y de la otra, y por eso existían muchas enemistades; y porque en el resto de la provincia de Guipúzcoa no se vedaban las armas. El Consejo Real se ordenó que se alzara el veto como cumple a nuestro serviçio e al bien e paz e sosiego de la dicha tierra e vesinos e moradores della: AGS, RGS, leg. 149101, exp. 199. 
sona; y hasta en un $24,5 \%$ más se permitió que la acompañasen exclusivamente uno o dos hombres ${ }^{43}$. El problema se produciría en el $15 \%$ de licencias restantes, donde cuatro o más personas fueron autorizadas, en una suma poco precisa ${ }^{44}$.

\begin{tabular}{|c|c|c|c|}
\hline \multicolumn{2}{|c|}{$\begin{array}{l}\text { ADJUDICACIÓN DE HOMBRES } \\
\text { ARMADOS EN LICENCIAS } \\
\end{array}$} & \multirow{2}{*}{\multicolumn{2}{|c|}{$\begin{array}{c}\text { TOtAL DE } \\
\text { HOMBRES ARMADOS }\end{array}$}} \\
\hline N. ${ }^{\circ}$ de hombres & $\mathrm{N}{ }^{\circ}$ de licencias & & \\
\hline 1 & 210 & 210 & \multirow{11}{*}{613} \\
\hline 2 & 34 & 68 & \\
\hline 3 & 49 & 147 & \\
\hline 4 & 12 & 48 & \\
\hline 5 & 9 & 40 & \\
\hline 6 & 5 & 30 & \\
\hline 7 & 1 & 7 & \\
\hline 8 & 1 & 8 & \\
\hline 9 & 2 & 18 & \\
\hline 14 & 1 & 14 & \\
\hline 18 & 1 & 18 & \\
\hline Grupos indeterminados & 19 & & \\
\hline Colectivo & 1 & & \\
\hline Total de licencias & 345 & & \\
\hline
\end{tabular}

Esencialmente los mecanismos con que contaban los consejeros reales a la hora de evadir los peligros de toda licencia grupal eran tres. Por un lado, la referida solicitud de fianzas. En todos los casos había de existir uno o varios responsables, a los que reclamar unas fianzas cuantiosas en depósito, en poder de las autoridades de su población, como garantía de que el armamento solo se utilizaría de una manera apropiada. Por otro lado, la merced a quienes integraban los grupos solo tenía vigor en tanto que escolta; en la medida en que acompañasen al sujeto que había pedido ayuda, no cuando no se hallaran junto a él. Se trataba de una concesión restringida; muy condicionada en el tiempo y en el espacio. Por último, también era importante la relación existente entre el Consejo y la persona que solicitaba su favor. Algunos peticionarios eran conocidos, de linajes nobles cuya lealtad era palmaria, lo que hacía suponer que no iban a utilizar sus salvoconductos para socavar el orden. Individuos

43 En el 9,85\% se permitió la presencia de un acompañante armado. En el 14,2\% la de dos.

44 Por ejemplo, se concedió licencia para que se armasen el comendador Bernal Mexía, vecino de Madrid, y los suyos como medida de protección frente a los pleitos que trataban con otras personas de esa villa: AGS, RGS, RGS, leg. 147709, exp. 583. 
como Francisco Fernández de Córdoba ${ }^{45}$, o Hernando de Luján ${ }^{46}$. O el salmantino Alfonso de Fonseca, autorizado a llevar ocho hombres en compañía porque ${ }^{47}$

... syn cabsa nin culpa suya él tyene fenemigos que fan ynsydiado e ynsidian su vida e fonrra, e dis que fan puesto por obra de le matar e ofender, e dis que como son naturales desa çibdad donde él bive, e están e tyenen debdos en ella, a él por seguridad de su persona e fonrra dis que le conviene que los escuderos que con él biven traygan armas, porque él se pueda defender e porque sus fenemigos, viendo que anda a recabdo, no tengan atrevimiento de le ofender...

Aunque en gran parte nos es desconocida la intrahistoria que se encontraba detrás de las solicitudes de auxilio a los reyes, existían varias razones por las cuales el Consejo se podía ver forzado a conceder su aprobación a un grupo. En un principio, la causa más determinante estaría relacionada con el "grado de peligrosidad» que se cernía sobre los demandantes. Hernando de Nonza, por ejemplo, un vecino de la villa de Valmaseda, por sí y en nombre de Rodrigo Angulo y del bachiller Bernardino del Rebollar denunció que Rodrigo de Noceda, en un día del mes de jullio pasado [de 1498], dis que puso sobre açechanças a matar al dicho bachiller, e dis que le tiró muchos golpes e cuchilladas, de las quales le mataría sy non fuera porquel dicho Fernando de Nonça e el dicho Rodrigo de Angulo se le defendieron ${ }^{48}$. En una fecha anterior, en torno a 1472, Andrés de Soria, vecino de Murcia, había partido de su ciudad hacia Lorca con el fin de casarse, llevando consigo 120000 maravedíes en dinero y en joyas. Ese mismo día fue hallado exánime, con dos lanzadas, en la ribera del río Segura, a una legua de la urbe; e que a la sasón ninguna guerra ni movimiento avía en todo el reyno de Murçia, de la qual dicha muerte e robo dis que non se pudo saber la verdad... Años más tarde, en 1480, la madre del difunto, que habitaba en Valencia, descubrió quién había acabado con la vida de su hijo, marchó a Murcia y solicitó al corregidor que hiciera justicia, acusando a un tal Juan de Ayala, «el de Albudeite». Esto generó un conflicto ${ }^{49}$, ante el que Alfonso de Avellán, un pariente de Andrés de Soria, reclamó una licencia de armas al Consejo, otorgándosele a él y a cuatro de sus continos comensales ${ }^{50}$.

Aparte de lo peligroso de la situación, otros condicionantes de peso para conseguir una licencia tenían que ver con razones como la excepcionalidad de las circunstancias. Llegaron a concederse salvoconductos ante la conclusión de órde-

45 AGS, RGS, leg. 150010, exp. 22.

46 AGS, RGS, leg. 150001, exp. 14.

47 AGS, RGS, leg. 149806, exp. 3.

48 AGS, RGS, leg. 149809, exp. 4.

49 Desconocemos si este Juan de Ayala es el mismo que solicitó una licencia de armas en 1485 por la gran enemistad que le tenían algunas personas en Murcia, logrando un salvoconducto tanto para él como para dos de sus criados: AGS, RGS, leg. 148502, exp. 20.

50 AGS, RGS, leg. 148006, exp. 259. 
nes de destierro ${ }^{51}$, por haberse quebrantado un seguro ${ }^{52}$ e, inclusive, contra la justicia local, para hacer frente a la actitud arbitraria de algunos de sus integrantes ${ }^{53}$. Aun así, existían factores con mucha más preeminencia, como los relativos a la mencionada buena relación con la corte y, sobre todo, el desempeñar en ella un oficio. Estos dos requisitos hicieron que obtuvieran autorizaciones para circular con armas y escolta tanto criados $^{54}$ y vasallos de los reyes ${ }^{55}$ como hombres que tenían o habían tenido responsabilidades en el entorno institucional de la monarquía, como maestresalas $^{56}$, menestreles ${ }^{57}$, escuderos de pie de la reina ${ }^{58}$, alcaldes ${ }^{59}$ y alguaciles de la casa $y$ corte $^{60}$, reposteros $^{61}$, capitanes de la armada $^{62}$, alféreces mayores ${ }^{63}$, alcaldes de las sacas $y$ cosas vedadas ${ }^{64}$ o veedores de la gente de las guardas ${ }^{65}$. La cercanía a la corte y/o a los reyes era un aval a la hora pedir cualquier clase de dispensa.

En efecto, el serviçio a los monarcas podía ser determinante a la hora de conseguir no solo un salvoconducto, sino una escolta de hombres armados. Todo era más fácil si las coacciones y las amenazas se producían trabajando para la corte, o para los reyes ${ }^{66}$; o si eran fruto de ostentar un oficio público en el ámbito regional o municipal, como el de comendador ${ }^{67}$, preboste ${ }^{68}$, procurador $^{69}$, regidor ${ }^{70}$, dipu-

51 AGS, RGS, leg. 148607, exp. 6. AGS, RGS, leg. 149212, exp. 91.

52 AGS, RGS, leg. 148501, exp. 14.

53 Rodrigo, Fernando y Pedro Sánchez, vecinos de la villa de Castromocho, señalaron ante el Consejo quel corregidor desa dicha villa e otras personas con él puede, aver un año, poco más o menos, dis que ficieron matar al dicho Rodrigo Sánchez en la dicha villa e le tomaron faserlo meter en la yglesia, $e$ que a esta cabas el dicho corregidor e las otras personas lo quieren mal. AGS, RGS, leg. 149812, exp. 10.

54 AGS, RGS, leg. 147801, exp. 79.

55 AGS, RGS, leg. 147809, exp. 151; AGS, RGS, leg. 150107, exp. 28.

56 AGS, RGS, leg. 147902, exp. 4.

57 AGS, RGS, leg. 150102, exp. 25.

58 AGS, RGS, leg. 148503, exp. 14; leg. 149103, exp. 5.

59 AGS, RGS, leg. 148909, exp. 303.

${ }^{60}$ AGS, RGS, leg. 149402, exp. 128.

${ }^{61}$ AGS, RGS, leg. 149012, exp. 10; leg. 149207, exp. 2.

62 AGS, RGS, leg. 149403, exp. 13.

63 AGS, RGS, leg. 150009, exp. 29.

${ }^{64}$ AGS, RGS, leg. 149907, exp. 7.

65 AGS, RGS, leg. 150104, exp. 83.

${ }^{66}$ El caballero Andrés González, vecino de la ciudad de Huete, se quejó a la reina diciendo que por él faser algunas cosas conplideras a mi serviçio y al bien y pro común de mis reynos y a honor de la corona real dellos contra algunas personas que estavan en mi deserviçio, que las tales personas le tienen odio e enemystad e se reçela dellos que [le] ferirán o matarán, o mandarán ferir o matar, o faser otro mal e dapno en su persona e bienes: AGS, RGS, leg. 147708, exp. 420. Gutierre Fernández del Campo, vecino de Ciudad Real, había entendido algunas cosas cumplideras al servicio de la monarquía: AGS, RGS, leg. 148804, exp. 8. Francisco de Zorita, por su parte, había servido a la corona notificando en la corte algunos crimenes y delitos que se habían cometido en su ciudad: AGS, RGS, leg. 149302, exp. 235.

67 AGS, RGS, leg. 148009, exp. 275.

68 AGS, RGS, leg. 148405, exp. 16; leg. 148812, exp. 17.

${ }^{69}$ AGS, RGS, leg. 149306, exp. 13.

70 AGS, RGS, leg. 148901, exp. 118; leg. 150006, exp. 13; leg. 150101, exp. 14; leg. 150103, exp. 32; leg. 150107, exp. 25. 
tado $^{71}$, alcaide ${ }^{72}$ o lugarteniente de los alcáçares ${ }^{73}$. En algunos casos, dadas las buenas relaciones del demandante con la corona, el Consejo ni siquiera pedía fianzas o el desarrollo de una investigación para comprobar la veracidad de los alegatos, sino que, sin cláusulas limitadoras, directamente ofrecía el salvoconducto para andar con armas por todo el reyno. Por ejemplo, ante la demanda de Pedro de Alcalá, un regidor de Cuenca, según la cual Diego Hurtado de Mendoza, vasallo de los reyes y guarda de la urbe, le tenía fenemystad, a causa que usando de su ofiçio de regidor fa contradicho algunas cosas en el regimiento de la dicha çibdad que tocan al dicho Diego Furtado, se replicó que, visto por los del nuestro Consejo, por quanto les constó lo susodicho ser asý, había de concederse la licencia al solicitante y a dos de sus hombres en acompañamiento ${ }^{74}$.

Por desgracia, apenas se conoce en qué deparó el empleo de este tipo de mercedes para facultar a catervas armadas de hasta treinta o cuarenta individuos, incluyendo a los peticionarios de las solicitudes y a sus núcleos de familia, a sus parientes y a su clientela social: desde criados, continuos y apaniaguados a esbirros coyunturales -en ocasiones contratados solo para proteger al grupo-. En la lucha de intereses en que se movían los poderosos el empleo de hombres de armas era habitual, tanto con el fin de defender las vidas y las pertenencias de los integrantes de sus facciones como, especialmente, con el objetivo de sembrar el caos y hacer que, dada la quiebra del orden público, se necesitase un cambio en el gobierno, del que se pudieran beneficiar quienes la habían provocado ${ }^{75}$. En consecuencia, los grupos constituidos con la venia del Consejo, cuyo fin, en teoría, era proteger a personas cuya existencia se hallaba bajo amenaza, habrían de convivir en las calles con otros grupos de hombres armados a las órdenes de oligarcas que, mediante la intimidación, querían dejar claro su poder. En teoría, porque, de hecho, en la práctica resultaba difícil, si no imposible, distinguir entre grupos «autorizados» y no autorizados.

A veces -se desconoce con qué frecuencia-, los permisos para portar armamento se utilizaban con fines que no eran los argumentados ante la monarquía, o se explotaban con arbitrariedad, excediendo las prerrogativas sancionadas en las credenciales. En el año 1480, por ejemplo, se autorizó a llevar armas a catorce personas de Palencia, ante el auxilio que habían demandado en el Consejo Real el comendador Antonio de Merodio, Gómez de Merodio, Pedro de Merodio, Juan Gutiérrez de Quirós, Juan Zamorano, Juan del Hierro, Toribio Cartero, Aparicio y Felipe, ante las questiones e debates que tenían con Diego de Saldaña y su hermano Álvaro, $y$ con otros parientes suyos ${ }^{76}$. Se trataba de una autorización magnánima, que per-

71 AGS, RGS, leg. 149912, exp. 2; AGS, RGS, leg. 150012, exp. 14.

72 AGS, RGS, leg. 150012, exp. 13.

73 AGS, RGS, leg. 150006, exp. 16.

74 AGS, RGS, leg. 150105, exp. 17.

75 Lop Otín, María José y López Gómez, Óscar, «Entre la paz y el caos. Acción subversiva y actividad pacificadora en las élites urbanas. Toledo, 1441-1495». Hispania: Revista española de historia, 2015, vol. 75/250, 413-440.

76 AGS, RGS, leg. 148009, exp. 275. 
mitía organizar un grupúsculo vigoroso, de cuyas actuaciones posteriores, en todo caso, no hay referencias. Sí existe información, por el contrario, de unos hechos que tendrían lugar en Trujillo.

$\mathrm{Al}$ igual que en el caso anterior, en 1491 algunos vecinos de Plasencia, Cáceres y Trujillo lograron que, de forma colectiva, el Consejo los autorizase a ir con $\operatorname{armas}^{77}$. Su solicitud, sin embargo -según los datos que tenemos-, había sido peculiar, porque si bien, como otras solicitudes, se había justificado en un supuesto temor a padecer alguna variedad de perjuicio por culpa de la acción de unos contrincantes, los peticionarios no eran de la misma urbe, y no estaba claro el vínculo que los unía. Aun así, y a riesgo de estar armándose a una lyga e monopodio, a una parçialidad con fines desconocidos, el Consejo los facultó para que cada uno de ellos pudiera traer armas junto a dos escuderos, y para que pudieran armarse, también, sus servidores y familiares. Si se había calibrado o no la posibilidad de que estuviera ofreciéndose a una facción una vía para acudir a las armas es algo que no se sabe, aunque, de todas formas, unos meses después, en 1493, el propio Consejo Real se haría eco de una denuncia de los regidores de Trujillo, los cuales aseguraban que Cristóbal Pizarro y sus prosélitos Altamirano y Loaysa ${ }^{78}$

... traen armas públicamente estando por vos vedadas e defendidas, diziendo que para ello tienen nuestra liçençia, los quales diz que son personas de vando, e que en traer ellos las dichas armas otros cavalleros e personas de la dicha çibdad reçiben agravio. E nos fue suplicado e pedido por merçed çerca dello mandasemos proveer, mandando que a todos se vedasen generalmente las dichas armas, o que sy ellos las oviesen de traer mandasemos dar lugar asýmesmo a otros cavalleros de la dicha çibdad para las traer...

La respuesta fue meridiana:

... vos mandamos que non consintáys nin deys lugar a los susodichos nin a otra persona alguna de esa dicha çibdad que traygan armas en ella, e lo defendades a todos egualmente, non enbargante que para ello tengan liçençia nuestra, salvo sy alguna de las tales personas que asý las traxeren con nuestra liçençia vieredes vos que tienen justa causa e tal nesçesidad para que las devan traer, y le dieredes logar a ello, por el tienpo contenido en la dicha nuestra liçençia que asý toviere, lo qual fazed e conplid de manera que unos non tengan más libertad que otros para poder traer las dichas armas, salvo en la forma susodicha...

77 Gutierre de Carvajal, Luis de Carvajal, García López de Carvajal y Gonzalo de Carvajal, hijo del dicho Gutierre, y Sancho de Figueroa, vecinos de la ciudad de Plasencia, y Cristóbal Pizarro, vecino de la ciudad de Trujillo, y Juan de Sande de Carvajal, vecino de la villa de Cáceres: AGS, RGS, leg. 149103, exp. 23.

78 AGS, RGS, leg. 149301, exp. 150. 
La situación no debió solucionarse a pesar de este mandato, porque en 1494 hubo otra queja de Francisco de Carvajal, que volvió a conseguir una licencia de $\operatorname{armas}^{79}$ :

... que algunas personas de la dicha çibdad de Troxillo le dieron çiertas feridas, e que demás desto le fan amenazado porque sygue su justiçia, e contra él, que le fan de matar e ferir sy putieren [ferir sy pudieren aparece tachado], e que para en su defensyón e se guardar de sus enemigos le cumple trafer armas, él e otros dos criados suyos que anden con él, porque las tales personas que le dieren las dichas feridas dicen que lo fan de matar, e son cavalleros e personas emparentadas en la dicha çibdad de Troxillo e su comarca...

Lo mismo ocurriría en el año 1497. Gonzalo, García, Alfonso y Francisco Pizarro, Francisco de Loaysa y Gonzalo de la Torre, vecinos de Trujillo, certificaron que Benito y Francisco Pizarro y Juan Calderón habían matado a su pariente Juan Pizarro. Según su testimonio, el juez de residencia de la ciudad, el licenciado de Salinas, había ido contra los malhechores hasta condenarlos a pena de muerte, y

... los dio por enemigos capitales a todos los parientes dentro del cuarto grado del dicho Juan Pizarro, para que do querría que los pudiesen aver los puedan matar libremente, syn pena alguna...

Por miedo a ser agredidos de tropezarse con los agresores, y por la necesidad tener las armas a mano de ocurrir de ese modo -para ejecutar la pena de muerte instituida-, se consintió su solicitud, armándose a los peticionarios, de nuevo, aunque, eso sí, siempre que, en primer lugar, el corregidor de Trujillo hiciera una investigación sobre el caso, y depositaran unas fianzas suficientes ${ }^{80}$.

\section{MOTIVACIONES DE LAS LICENCIAS DE ARMAS}

Las motivaciones que otorgaban legitimidad a los permisos para ir con armamento tenían que ver, por lo común, con disputas enquistadas cuya resolución brutal se preveía inminente. No se trataba de hechos acaecidos en épocas remotas, sino de la violencia, el crimen y la conflictividad del momento: de un escenario de confrontación latente, donde las animadversiones discurrían por una senda peligrosa, en la que era factible el paso de las amenazas, los insultos y el espionaje a la agresión física o el homicidio ${ }^{81}$. En algunas credenciales, de hecho, se recogía una especie de catálogo de las contingencias a las que se enfrentaban los peticionarios: muertes, heridas, lesiones, prendimientos, embargos, u otro mal o dapno o desaguisado

\footnotetext{
79 AGS, RGS, leg. 149407, exp. 24.

80 AGS, RGS, leg. 149711, exp. 7.

81 AGS, RGS, leg. 149111, exp. 108.
} 
alguno en su persona e bienes... ${ }^{82}$. La posibilidad de morir o de acabar en la ruina a causa de los odios, enemistades e malquerençias era una argumentación reiterada a la hora de pretender el auxilio de la corona, aunque, con toda seguridad, los testimonios a menudo no serían fidedignos, sino que -como pasaba con otros documentos relacionados con la violencia- se emplearían clichés agravantes, para facilitar la concesión de la merced. Así, en un elevadísimo número de casos las razones legitimadoras serían falsas, o al menos velarían parte de la verdad, en aras de conseguir salvoconductos cuyos objetivos no siempre eran tranquilizadores ${ }^{83}$.

El propio Consejo solía dudar sobre lo que se le planteaba, por lo que era frecuente que exigiera hacer una averiguación a autoridades inferiores, próximas al peticionario. De esta manera, con semejante mesura, se pasaba la responsabilidad a los gobernadores de las distintas localidades, pidiéndoles que solo diesen vía libre a los salvoconductos que los propios consejeros habían acreditado si, en efecto, ellos así lo consideraban, una vez concluidos los informes y recibidas las fianzas. Por desgracia, no sabemos cómo se gestionaron por parte de la administración municipal las mercedes concedidas, ni hasta qué punto se admitieron, o no. Como hasta los ańos 80 del siglo xv las solicitudes para llevar armamento eran reducidas, el propio Consejo recababa la información que creía oportuna para avalar su tarea. Ulteriormente, cuando los solicitantes fueron en aumento, dejaron de hacerse averiguaciones, excepto en un reducido número de casos referentes a personas de la corte o a sucesos escabrosos; y se delegó ese cometido en las autoridades de cada villa o ciudad ${ }^{84}$.

\begin{tabular}{|cc|}
\hline \multicolumn{2}{c}{$\begin{array}{c}\text { MOTIVOS POR LOS QUE SE SOLICITAN } \\
\text { LICENCIAS DE ARMAS }\end{array}$} \\
\hline Enemistad & 153 \\
\hline Intervención de la justicia & 71 \\
\hline Seguimiento de la justicia & $(9)$ \\
\hline Proceso por homicidio & $(14)$ \\
\hline Proceso por agresión & $(11)$ \\
\hline Proceso por adulterio & $(15)$ \\
\hline
\end{tabular}

82 AGS, RGS, leg. 147806, exp. 104.

83 Por ejemplo, tras el asesinato de Francisco Godínez en la villa de Cazorla a manos de Juan Benizar y de Lorenzo Páez, vecinos de Valladolid, los hermanos del muerto, Juan Godínez y Tomás Godínez, y Pedro de Aravaca alegaron ante el Consejo que se había condenado a los agresores a pena de muerte y habían huido, e quellos han de andar buscando los dichos matadores para que sea executada en ellos la nuestra justiçia, e les conviene traer armas para en su defensyón. Los consejeros escribieron a las autoridades de Cazorla, Veas y Villanueva del Arzobispo para solicitarles que hiciesen información, y que, solamente si lo alegado era verídico, y tras dar fianzas que avalasen que el armamento se usaría con fines defensivos, y no para ejercer la venganza, se permitiera llevar armas tanto a los solicitantes como a dos individuos de escolta: AGS, RGS, leg. 149803, exp. 20.

84 Cruces Blanco, Esther, «Orden público y violencia en la ciudad de Málaga a fines del siglo xv y principios del siglo Xvi (1495-1516)». Meridies, 1995, vol. 2, pp. 121-143, en concreto p. 134. 


\begin{tabular}{|cc|}
\hline Proceso por violación & $(1)$ \\
\hline Proceso por herencia & $(3)$ \\
\hline Pena de muerte por homicidio & $(11)$ \\
\hline Pena de muerte por agresión & $(1)$ \\
\hline Pena de muerte por adulterio & $(2)$ \\
\hline Pena de muerte por violación & $(1)$ \\
\hline Pena de muerte & $(1)$ \\
\hline Encarcelamiento & $(1)$ \\
\hline No se indica & $(1)$ \\
\hline Cuestiones, diferencias y debates & 39 \\
\hline Violencia & 35 \\
\hline Agresión & $(17)$ \\
\hline Homicidio & $(15)$ \\
\hline Alboroto & $(3)$ \\
\hline Servicio en cargo público & 28 \\
\hline Servicio a los reyes & 10 \\
\hline No concesión de perdón por muerte & 5 \\
\hline Solicitud de ayuda a la corte & 1 \\
\hline Ocupación de fortaleza & 1 \\
\hline Fin suntuario & 1 \\
\hline Viaje por el reino & 1 \\
\hline TOTAL & 345 \\
\hline
\end{tabular}

Era imperioso que la gestión de los permisos quedara en manos de los regidores de las villas y ciudades, porque ellos conocían en persona a los peticionarios de ayuda en la corte. Eran los únicos que podían impedir que las licencias acabasen en poder de facinerosos que las emplearan de forma clandestina, con una falsa identidad. Empero, el tener que recurrir a la honestidad de la persona que reclamaba ayuda y a la mediación de las autoridades locales hizo que, muy asiduamente, los consejeros prefirieran, en vez de adjudicar permisiones para ir con armas, poner a los demandantes de su socorro so su defendimiento, amparo e seguro real, es decir, bajo su salvaguardia, de forma que los que los atacasen hubieran de verse sometidos a un mayor rigor judicial, enfrentándose a penas más duras. El número de amparos e defendimientos fue siempre mayor que el de licencias de armas, porque, si bien se trataba de una protección menos efectiva - no tan inmediata ni directa-, era un auxilio que no quedaba en manos de las víctimas ni de las autoridades municipales, y que, por consiguiente, exigía menos precaución. Los seguros soslayaban los fines negativos que podían conllevar las licencias; así que si no se pudo recurrir a ellos fue por incapacidad: porque ciertas amenazas requerían una protección que no debía coartarse, aunque al quedar en poder de los intere- 
sados y de otros regidores se reconocieran, de hecho, los límites de la realeza a la hora de amparar a sus súbditos.

\subsection{ENEMISTADES, ODIOS E MALQUERENÇIAS. El LACONISMO EN LAS JUSTIFICACIONES}

La incidencia del conflicto en algunas villas y ciudades queda ratificada en virtud de la vecindad de quienes acudieron en búsqueda de un socorro armado ante el Consejo de Castilla. A pesar de sus más de cien procedencias geográficas, fue a los vecinos de tres localidades a quienes se expidió un mayor número de salvoconductos para circular con armamento: los de Salamanca, una ciudad en la que tuvo una enorme influencia la lucha de facciones ${ }^{85}$; los de Toledo, donde también existían diputas entre parcialidades, que se mezclaban con el delito, sembrando el caos ${ }^{86} ; \mathrm{y}$ los de Valladolid, se supone que no solo por la conflictividad de la población, sino por permanecer en esta villa el Consejo a lo largo de grandes temporadas ${ }^{87}$.

Aparte de la vecindad, los datos sobre las circunstancias de quienes pidieron el favor de la corona son casi inexistentes. En pocas ocasiones se referían sus ocupaciones o sus estatus. Como se indicó, con frecuencia se trataba de miembros de la corte, o de individuos a su servicio, cuando no de integrantes de las oligarquías ciudadanas. Y de no ser así, de referirse alguna profesión, se solía tratar de mercaderes, plateros, tejedores de seda, carpinteros, pintores o albañiles; en definitiva, de gente del común que gozaba de una fluidez económica suficiente como para soportar los gastos del desplazamiento a otros territorios y las gestiones ante el Consejo. Salvo alguna excepción, no se trataba de caballeros. Pero tampoco de personas con un nivel de vida estándar. En el amplio sector social del común probablemente serían parte de su élite, dado su poderío económico. Lo avala el que, en un número de ocasiones no poco relevante, temieran no exclusivamente por sus vidas y las de los suyos sino, también, por sus bienes -talleres, palacios, joyas, dinero, animales-;

85 López Benito, C.I., Bandos nobiliarios en Salamanca al iniciarse la Edad Moderna. Salamanca, 1983; Monsalvo Antón, José María, «Aspectos de las culturas políticas de los caballeros y los pecheros en Salamanca y Ciudad Rodrigo a mediados del siglo xv: violencias rurales y debates sobre el poder en los concejos", en Alfonso Antón, María Isabel y Escalona Monge, Lulio (coord.), Lucha politica: condena y legitimación en la España medieval, Madrid, 2004, pp. 237-296.

${ }^{86}$ López Gómez, Óscar, La sociedad amenazada. Crimen, delincuencia y poder en Toledo a finales del siglo XV. Toledo, 2006; Los Reyes Católicos y la pacificación de Toledo. Madrid, 2008.

${ }^{87}$ Majo Tomé, Beatriz, «Control de la actividad cotidiana y preservación de la paz social en Valladolid a fines de la Edad Media y principios de la Edad Moderna», en Mundos medievales: espacios, sociedades y poder: homenaje al profesor José Ángel García de Cortázar y Ruiz de Aguirre, 2012, vol. 2, pp. 1549-1560; «Los conflictos sociales en Valladolid en el tránsito de la Edad Media a la Edad Moderna en los libros de actas del concejo», en Solórzano Telechea, Jesús Ángel y Arízaga Bolumburu, Beatriz (dir.), La gobernanza de la ciudad europea en la Edad Media, Logrońo, 2011, pp. 567-586; «Valladolid: un señorío colectivo a fines de la Edad Media. Estrategias de control y conflictividad", en Carvajal de la Vega, David, Vítores Casado, Imanol y Añíbarro Rodríguez, Javier (coord.), Poder, fisco y mercado en las ciudades de la Península Ibérica (siglos XIVXVI), Madrid, 2016, pp. 259-275 


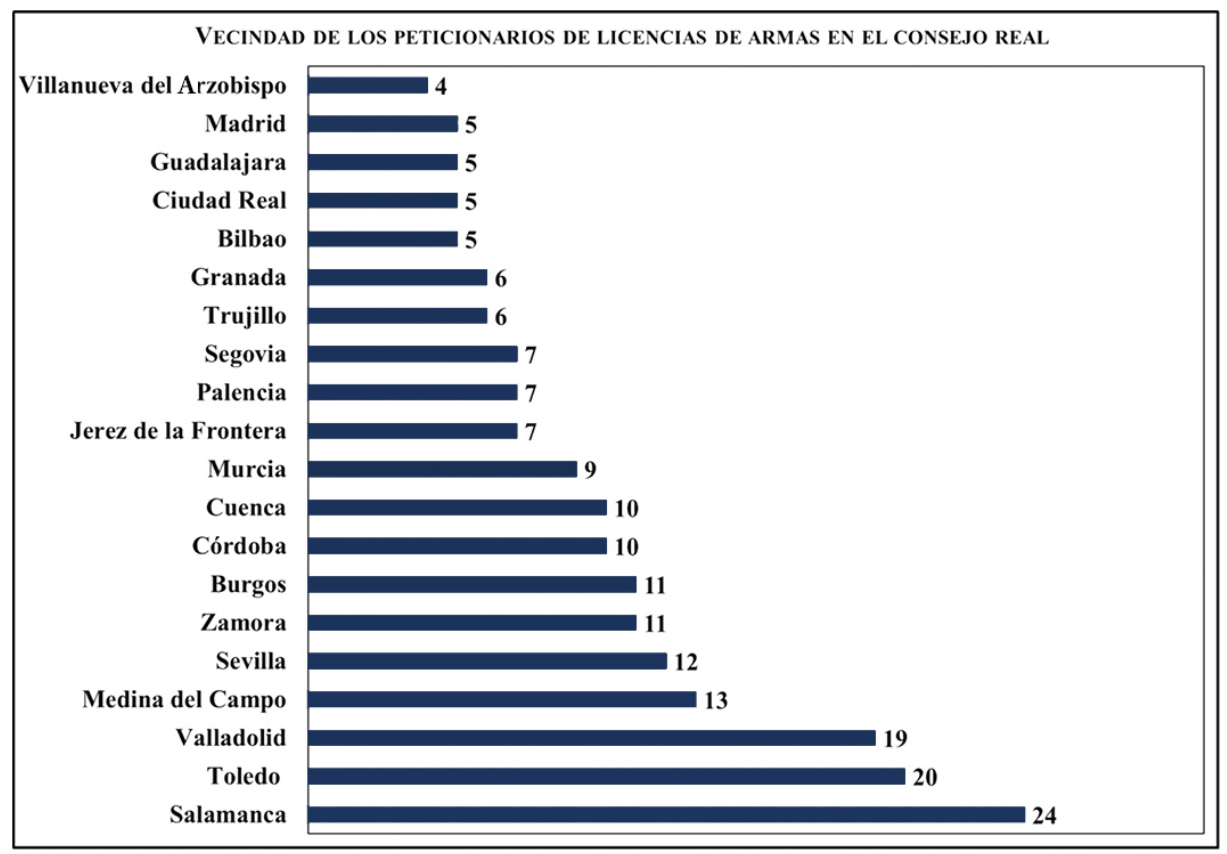

y que solicitaran llevar armas no solo ellos, sino sus servidores y sus criados, lo que indica que contaban con una clientela social.

Uno de los rasgos de las licencias de armas es su laconismo; también en lo que se refiere a la información sobre las razones que las habían motivado. Aparentemente ante los consejeros se habría presentado una información más o menos detallada en torno a los problemas que movían a realizar las solicitudes, pero en la concreción de las mismas en un documento oficial no solían referirse los detalles, haciéndose tan solo un resumen sucinto y sesgado -en ocasiones una o dos líneas-, con el fin de presentar ciertos hechos como lo bastante embarazosos como para permitir a la realeza colocar a una persona al margen de las leyes municipales, al permitirle traer armamento. Las licencias de armas, en consecuencia, no sirven para establecer un supuesto modelo de criminalidad, aunque nos permitan acercarnos al crimen de una manera privilegiada ${ }^{88}$.

Era común -en el $44,43 \%$ de los casos- que de forma genérica se justificase lo requerido en función de una supuesta enemistad, odio e malquerençia, sin ofre-

88 González Zalacaín, Roberto, El perdón real en Castilla a fines de la Edad Media. El ejemplo de la Cornisa Cantábrica. Bilbao, 2013. Coincidimos con la honestidad de las puntualizaciones en lo referente a este modelo que señala Juan Miguel Mendoza Garrido en Delincuencia y represión en la Castilla bajomedieval (los territorios castellano-manchegos). Granada, 1999. 
cerse más explicaciones. Solo en alguna ocasión se llegaba a detallar a qué se debía la discordia ${ }^{89}$, y, de hacerse, se planteaban excusas, defendiendo que los motivos que habían llevado a la hostilidad no los habían iniciado los solicitantes; que si estaban enemistados e tienen enhemigos era syn su culpa $a^{90}$; o que ni siquiera existía una razón que justificara las desavenencias ${ }^{91}$. Por ejemplo, Pedro Bayle, vecino de la villa de San Martín de Trevejo, se quejó de que Juan de Villalobos, alcaide del castillo de Corbejo, sus hombres y sus familiares le tenían gran odio y enemistad syn culpa e cabsa suy $a^{92}$. Lope de Salazar, por su parte, vecino de la villa de Laredo, aseveraba que andaría con mucho peligro de no traer armamento, porque tenía enemistades con algunas personas syn cabsa nin culpa suya, espeçialmente Juan de Alanbari, que diz que está sentençiado e açotado ${ }^{93}$. Según Diego de Olivares, vecino de Toledo94:

... un día, corriendo un caballo, tropelló a una muger, de que murió, e que nuestra justiçia, viendo que estava syn culpa, le dio por libre e quito, e que a esta causa causa (sic) sus parientes e otras personas le quieren mal...

Se trataba de argumentos atenuantes, manipuladores y posiblemente cargados de falsedad, que no deben llevarnos a establecer una diferenciación diáfana entre víctimas -quienes solicitaban el socorro de la corona-y opresores. La realidad era más compleja. Los salvoconductos para traer armas podían resultar muy útiles en el desarrollo de los conflictos. Con ellos se lograba que se posicionasen instituciones del poder del Consejo Real. Evidentemente servirían para defender las vidas y los bienes de los peticionarios, pero de igual modo para colocarlos en una situación de privilegio, de cara a resolver sus disputas de una forma propicia.

En este sentido, en 39 de las 345 licencias analizadas -en el 11,3\%- se hablaba de cuestiones, debates o diferençias a la hora de referir un enfrentamiento, sin aclarar ni los motivos ni lo que había pasado hasta entonces. Semejante argumentación, ambigua, abstracta y escasamente aclaratoria, no nos permite tampoco entrever los entresijos por los que se habían desarrollado las disputas y, ni siquiera, a menudo, no culpabilizar a los propios solicitantes ${ }^{95}$. En ocasiones se hablaba de un

89 Por ejemplo, tras la muerte de Alvar Tintorero, vecino de Toledo, a manos de Alfonso de Écija, surgió entre los parientes de la víctima y el homicida odio e malquerençia, de forma que, aunque Alfonso se fue a servir a los reyes en la guerra de Granada para conseguir el indulto de su delito, los familiares de Alvar no solo no lo quisieron indultar, sino que, según Alfonso, querían matarlo, por conseguir venganza: AGS, RGS, leg. 148006, exp. 7.

90 AGS, RGS, leg. 149605, exp. 10.

91 AGS, RGS, leg. 149312, exp. 186.

92 AGS, RGS, leg. 148703, exp. 6.

93 AGS, RGS, leg. 149502, exp. 42.

${ }_{94}$ AGS, RGS, leg. 150107, exp. 30.

95 El bachiller Martín Fernández Andino, vecino de Salamanca, señaló que por causa que dize qu'él fue en la muerte de don Ýñigo destuñiga, vesino des dicha çibdad, él tiene algunos enemigos e otras personas que lo quieren mal: AGS, RGS, leg. 149501, exp. 7. 
intercambio de palabras entre los contendientes ${ }^{96}$, y de que se llegó a las manos ${ }^{97}$, pero lo habitual era que, de referirse un motivo, se apelara a la enemistad e malquerençia, o al odio. Una apelación fructífera, que servía para justificar cualquier cosa. Solo cuando conocemos lo que verdaderamente motivó una licencia parece claro que, al margen de las cuestiones referidas, del servicio a los reyes o en un cargo público, y de otras materias de menor relevancia ${ }^{98}$, existen dos asuntos que tuvieron enorme repercusión. Por un lado, todo lo relativo a la violencia. Y, por otro, lo referente al seguimiento de la justicia criminal.

\subsection{Más Allá de la ViolenCia y de LA JUSTICIA CRIMinal}

Los homicidios, los ataques y los abusos relacionados con una mujer -adulterios, violaciones, secuestros- llevaban implícita una obligatoriedad de venganza de la que los consejeros reales eran conscientes. No en vano, era habitual que antes de acudir a ellos se hubieran producido agresiones, en fechas próximas, aunque las síntesis de las mismas que se solían recoger en las licencias de armas deberían valorarse con suma cautela. El peticionario de ayuda en la corte siempre se presentaba como víctima, incluso de haber sido quien había perpetrado una muerte ${ }^{99}$; y se solía hablar de envites en acechanzas, de tajaduras en el rostro, de ausencias de perdón y de gravísimas injurias, y de amenazas de muerte. Por ejemplo, Nicolás de la Cárcel, vecino de Requena, aseguró que, hallándose seguro a las puertas de su casa, Diego de Santacruz le ovo dado una cuchillada en la cara, de que dis que le derrocó çiertos dientes $^{100}$. Cristóbal Zapata, un repostero de los reyes, yendo seguro por una de las calles de Vitoria se topó con Alfonso de Villarejo, cryado del reverendisymo cardenal d'España, que le propinó una cuchillada también en la cara, y a traición, por la cual, según dijo, llegó a punto de muerte; que nunca después acá an seydo amigos ${ }^{101}$. Alonso de Züñiga, por su parte, vecino de la villa de Becerril, aseguraba que había tenido un ruido en Medina de Ríoseco con Francisco Barroso, de Palencia, pero que

96 AGS, RGS, leg. 149802, exp. 4.

97 AGS, RGS, leg. 149909, exp. 19.

98 En el caso de Âlvaro de Atayde simplemente la solicitó porque necesitaba sentirse seguro a la hora de emprender un viaje por Castilla: AGS, RGS, leg. 148512, exp. 10. El musulmán Movalique, por su parte, contra las leyes, y fuera de lo que solía ser habitual, recibió una licencia con fines suntuarios, en su honra: ... para que libremente, sin contradiçión alguna, podades traer e traygades qualesquier vestidos, asi seda e grana como oro e plata e otras joyas. E asymismo podades trafer e traygades e cavalguedes en qualesquier cavallos que vos quisieredes e por bien tovieredes, e trafer e traygades armas de gineta en todas e qualesquier çibdades e villas y logares de nuestros reynos e señorios, non embargante qualesquier ordenanças que en contrario sean...: AGS, CCA, CED, 1, 62, 1.

99 Juan de Riofrío, vecino de Segovia, alegó que estando él salvo e seguro e syn armas en la çibdad de Toledo un hombre con una espada e un puñal le quiso matar, e quél defendiéndose dél con un puñal del dicho hombre le mató. AGS, RGS, leg. 149711, exp. 3.

100 AGS, RGS, leg. 149010, exp. 1.

101 AGS, RGS, leg. 149012, exp. 10. 
no hubo muerte ni cortamiento de miembro ni ferida de que saliese sangre, y, aun así, le amenazaban con matarlo ${ }^{102}$ : que jurava a dios e a santa Maria [...] que lo susodicho no lo dezía ni pedía maliçiosamente, salvo por muy grande e justo temor que tenía e tiene de la muerte, e por defensión de su vida e onrra... Juan Redelga, por último, un vecino de Zamora, se quejó en $1500^{103}$ :

... diziendo que podía aver dos ańos poco más o menos que estando él salvo e seguro diz que Juan de Bolaños, vezino de la dicha çibdad, fue con una espada sacada para le matar, e que le cortó del todo la mano derecha, e que él dio quexa dél ante la justiçia desa dicha çibdad, e que el corregidor que a la sazón fera le avía condenado en çiertas penas e cosas e dapnos que por ello avía resçibido, segúnd que en la dicha sentençia de que ante nos faze presentaçión se contenía, e que porque le fazían vender çiertos vienes que tenía para en pago dello diz que le amenaza, que la a de matar...

Dada su escasez y su poca fiabilidad, la información referida en los permisos para traer armas no permite un análisis profundo sobre la criminalidad de la época. Nunca se hace mención a lapsos temporales -épocas del año, momentos del día-, y en contadas ocasiones se puede situar espacialmente una agresión, si es que se había producido - ¿en una casa?, ¿en la calle?, ¡en el mercado?, ¿en una taberna?Y de ser así, tampoco suelen aparecer referencias al armamento empleado -solo, a veces, un puñal o una espada-. Ni siquiera existía una especificación en los propios permisos que concretase el tipo de armamento que se autorizaba a llevar. A priori, no había ninguna limitación, pudiéndose ir tanto con armas ofensivas como defensivas, siempre que se usasen para el amparo, y a no ser que los regidores correspondientes restringieran la merced $-o$ lo hiciese el propio privilegiado por la misma, por razones morales-, evitando transitar con artilugios cuyo empleo se estimaba deshonroso, como sucedía con las espingardas y las ballestas.

Más que de la violencia, de lo que nos hablan los permisos para traer armamento es de los límites de la justicia criminal, y de lo que podía ocurrir una vez sentenciado un homicidio o una agresión. En el 20,57\% de los casos se registraron como motivadores sucesos que tenían que ver con la justicia, a lo que debería ańadirse otro $10,14 \%$ en que se relataban episodios de violencia que, con toda seguridad -aunque no se especifique-, habían sido vistos por los jueces locales, antes de referirse en el Consejo. Por tanto, si no se contaran las justificaciones imprecisas - debates e cuestiones, malquerençias e odios- el tanto por ciento de causas en relación con la justicia y el crimen llegaría al 70\%. Se trataba de motivaciones relevantes a la hora de pedir auxilio: fuera para protegerse de la violencia, debido a una agresión, o fuera para garantizar el desarrollo de un proceso.

El desencadenante común era una riña entre un individuo, o alguien próximo a él, y otro u otros dos agresores. La trifulca no tenía por qué acabar en homicidio,

102 AGS, RGS, leg. 149111, exp. 108.

103 AGS, RGS, leg. 150010, exp. 23. 
pero eso no era óbice para que surgiera un enfrentamiento; que se solía enconar de requerirse la intervención de la justicia, porque eso conllevaba tres cosas: una renuncia explícita a los mecanismos infrajudiciales de resolución del conflicto, al recurso del empleo de árbitros o mediadores que contasen con la confianza de los contendientes ${ }^{104}$, lo que solía reducir los gastos, permitiendo proceder por cauces más amistosos; la entrada en juego de la coacción y el soborno, a la hora de condicionar a los en teoría imparciales jueces; y, por último, un no control del posible veredicto.

Cuando un enfrentamiento se judicializaba no se podían conocer cuáles serían las consecuencias. Muchos de los casos que dieron lugar a peticiones de socorro tenían que ver con procesos criminales por homicidio, adulterio o agresión, que, si bien ya estaban conclusos, habiéndose condenado a los culpables, en realidad aún no habían concluido, porque o bien los sentenciados habían huido, o bien sus familiares no habían aceptado la sentencia. De producirse una fuga, en lo referente a los delitos de sangre más espantosos se solía declarar a la familia de las víctimas fasta el cuarto grado en enemistad capital con los reos y los suyos ${ }^{105}$, otorgándoseles el derecho de ir en su contra hasta que se ejecutara la condena. En otros casos, eran los individuos juzgados, quienes, establecida su inocencia, reclamaban ayuda al Consejo Real porque sus oponentes no lo asumían ${ }^{106}$; o eran los propios jueces los que acababan sufriendo intimidaciones y ultimátums.

\section{A MODO DE CONCLUSIÓN}

La concesión de licencias de armas pone de manifiesto la coexistencia de distintas lógicas de resolución de los conflictos en la sociedad del siglo Xv. Una sociedad en la que, más allá de los diferentes rangos de cada individuo, y de la jerarquía de los linajes, la tensión cultural que empujaba al desquite, la venganza y el resarcimiento colisionaba con el poder punitivo del estado, lo que hace que los salvoconductos para transitar con armamento puedan ser evaluados desde una doble perspectiva. En primer lugar, en tanto que herramientas de gestión del conflicto, tal y como se apuntó en páginas anteriores.

En efecto, las licencias de armas eran símbolos de poder -aunque fuera un poder delegado, restringido y coyuntural-e instrumentos de coacción que podían repercutir en un mejor posicionamiento de quienes las portaban a la hora de afrontar sus disputas. No se trataba solamente de violencia, de miedo a la venganza y de

104 Royo Pérez, Vicent, «Árbitros y mediadores en el mundo rural valenciano durante la Baja Edad Media: Els Ports y El Maestrat (ss. XIII-XIV)». Espacio, tiempo y forma. Serie III, Historia medieval, 2019, vol. 32, pp. 379-412.

105 AGS, RGS, leg. 148410, exp. 2.

106 Los hermanos Diego y Vasquianes de Vega, vecinos de Valladolid, procedieron mediante la justicia criminal contra quienes habían violado a su hermana Teodora, que fueran condenados a muerte. Como huyeron de la justicia, ambos solicitaron una licencia de armas para ellos y cuatro de sus criados: AGS, RGS, leg. 149411, exp. 18. 
búsqueda de protección. Para los peticionarios de salvoconductos de semejante naturaleza el objetivo era hacerse con un documento que, garantizándoles la posibilidad de ampararse de ser atacados, los acreditara frente a sus oponentes como favorecidos por la corona: como personas con el dinero y la influencia necesarios como para movilizar a la maquinaria de la realeza en su beneficio.

Desde otra perspectiva, no obstante, las licencias de armas podrían definirse como un privilegio negativo, puesto que, en el fondo, más allá de sus fines coyunturales, eran la evidencia de un fracaso. Y no solo de quienes las requerían: de esos individuos que a diario estaban en la obligación de convivir con el desasosiego y la zozobra, temerosos de toparse con sus enemigos. No se trataba exclusivamente del fracaso de una persona. Cuando ante la violencia, las coacciones y el terror no había más remedio que otorgar una licencia de armas, para que las víctimas por sus propios medios combatiesen por sus vidas y las de los suyos, es indudable que el sistema político y judicial había fallado; no solo en los niveles inferiores de la administración, sino en términos de soberanía regia. La concesión de un salvoconducto en oposición a las prohibiciones establecidas era evidencia de los límites del poder regio a la hora de llevar a cabo su labor más relevante: proteger la vida de los súbditos. Había otros mecanismos no tan penosos, que reclamaban una intervención de los consejeros reales a la que se parecía renunciar con las licencias. Ese fin de defender al individuo podía conseguirse con mecanismos no tan comprometedores, como la concesión de seguros e amparos, pero con ellos la seguridad pasaba a depender de los reyes, mientras que con un permiso de armas era el sujeto que lo poseía el garante de su defensa. Los soberanos se apartaban del asunto. En beneficio de la víctima. Pero en descrédito de su imagen y su prestigio.

Las licencias de armas son un instrumento excepcionalmente valioso a la hora de asomarnos al ambiente de conflictividad social que se vivía en el siglo Xv en el seno de algunas sociedades. Eran resultado de disputas enquistadas cuya resolución era inviable por vías apacibles -como el recurso a mediadores, el desembolso de dinero con fines de desagravio, o el perdón-. En algunos casos, tras una solicitud de socorro se encontraba el miedo al desquite de unos enemigos. En otros, las licencias eran artilugios al servicio de quienes las solicitaban, en la medida en que con ellas podía lograrse el descrédito de los adversarios tanto desde un punto de vista social -debían seguir bajo la prohibición de traer armamento- como desde el punto de vista simbólico - no contaban con el apoyo de la monarquía-. El volumen de copias de licencias de armas que se nos conserva del Consejo Real de Castilla no admite análisis profundos sobre el crimen de la época, pero sí acercarnos a él desde una vía diferente: no solo entendido solamente como un fenómeno en el que entraban en juego la violencia y la justicia, sino, además, como el resultado de unas relaciones de poder en las que se pugnaba no por el predominio, sino por la simple supervivencia.

En este contexto las mujeres no solían ser protagonistas; y cuando lo eran su papel por lo común resultaba secundario. Tan solo en una de las 345 autorizaciones sometidas a evaluación podría entenderse que el Consejo facultaba a una mujer para transitar con armamento -a la salmantina Catalina de Miranda-, si bien la concesión no era para ella, sino para sus familiares y servidores. En los demás casos 
en que aparecen mujeres, en un total de 21 -el 6\%-, lo hacen como protagonistas subsidiarias; aunque esenciales, a la hora de consentir las licencias. Sobre todo son tres los acontecimientos vinculados a ellas que dan sentido a las solicitudes de ayuda en la corte: los secuestros, los adulterios y las violaciones. Como suele ocurrir en la documentación en torno a la criminalidad ${ }^{107}$, la honra vinculada a las mujeres era un tesoro cuya protección empujaba al desagravio y al resarcimiento, aunque en los salvoconductos ni siquiera se mencionaran sus nombres, y aunque a menudo se ofrecieran detalles escabrosos con el fin de legitimar lo solicitado que habría que poner en cuarentena ${ }^{108}$, dado su carácter justificador.

Ana de Bargas, Catalina Fernández, Teodora, María de Cubas, Catalina Jiménez o Inés de Baeza también tuvieron un rol destacado a la hora de conceder una licencia de armas, aunque fuera un rol nocivo, tal vez inmoralmente adjudicado; fruto, inclusive, de rumores pavorosos y testimonios deshonestos ${ }^{109}$. En la medida en que las autorizaciones se referían a las armas, se trataba de salvoconductos propios del género masculino: de algo que tenía que ver con la violencia -o, por lo menos, con la posibilidad de que fuese ejercida-, y con la pesada carga de tener que protegerse de unos enemigos -hombres, en todos los casos- que querían acabar con las vidas y las propiedades.

RECIBIDO: 5-8-2019; ACEPTADO: 11-9-2019

107 Val Valdivieso, María Isabel, «La acusación de adulterio como forma de ejercer violencia contra las mujeres en la Castilla del siglo XV». Estudios de historia de España, 2010, vol. 12/1, pp. 161-184; Fuente Pérez, María Jesús, «Más allá del amor: Mujeres moras y judías víctimas de violencia en la Castilla del siglo XV». Espacio, tiempo y forma. Serie III, Historia medieval, 2017, vol. 30, pp. 309-333; MARTín PÉREz, Fernando, “Paso contra ella carnalmente e ovo su virginidad por fuerça”. Justicia Real e impunidad social en el caso de la violación a Juana la Flor (San Vicente de la Barquera. 1487-1508)». Clio \& Crimen. Revista del Centro de Historia del Crimen de Durango, 2015, vol. 12 , pp. $125-154$

108 Pedro Gallego, un vecino de Palencia, indicó ante el Consejo que seyendo él legítimamente casado con María Ortega, su muger, dis que ella cometó adulterio con un Cristóval Martínez de Aguilera, alguasil que fue desa dicha çibdad el año pasado, a los quales dis que tomó juntos e desnudos en una casa en su casa. E como los halló junto dis que se fue a llamar a la justiçia, la qual dis que los prendió en la dcha cama, e que asý dis que están presos. E que a esta cabsa dis que él tiene algunos henemigos e otras personas que le quieren mal, parientes del dicho Cristóval Martínez de Aguilera...: AGS, RGS, leg. 149702, exp. 16.

109 Miguel de Zamora, vecino de Granada, atestiguó que porque, le fue levantado que se avýa echado con una fija de un Alvardero veçino de la çibdad de Toledo, fue preso por las nuestas justiçias, e después fue dado por libre e quito. E a esta cabsa él tyene algunos enemigos e otras personas que le quieren mal. AGS, RGS, leg. 150108, exp. 25. 